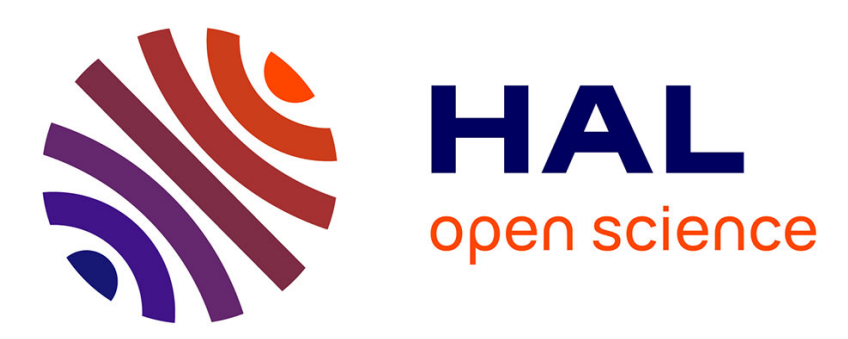

\title{
Segregation of Eucalyptus tereticornis Sm. clones for properties relevant to solid wood products
}

\author{
Shakti Chauhan, Aggarwal
}

\section{To cite this version:}

Shakti Chauhan, Aggarwal. Segregation of Eucalyptus tereticornis Sm. clones for properties relevant to solid wood products. Annals of Forest Science, 2011, 68 (3), pp.511-521. 10.1007/s13595-011-0053-

7. hal-00930788

\section{HAL Id: hal-00930788 \\ https://hal.science/hal-00930788}

Submitted on 1 Jan 2011

HAL is a multi-disciplinary open access archive for the deposit and dissemination of scientific research documents, whether they are published or not. The documents may come from teaching and research institutions in France or abroad, or from public or private research centers.
L'archive ouverte pluridisciplinaire HAL, est destinée au dépôt et à la diffusion de documents scientifiques de niveau recherche, publiés ou non, émanant des établissements d'enseignement et de recherche français ou étrangers, des laboratoires publics ou privés. 


\title{
Segregation of Eucalyptus tereticornis Sm. clones for properties relevant to solid wood products
}

\author{
Shakti S. Chauhan • Pankaj Aggarwal
}

Received: 9 June 2010 / Accepted: 8 October 2010 /Published online: 7 April 2011

(C) INRA and Springer Science+Business Media B.V. 2011

\begin{abstract}
- Introduction Wood quality is an important criterion in the selection of superior genotypes when breeding for solid wood. - Methods Fourteen clones of Eucalyptus tereticornis Sm. were assessed for wood quality namely basic density, acoustic velocity, longitudinal growth strain and volumetric shrinkage. The effectiveness of the pilodyn in screening trees according to wood density was also evaluated. The relationship between the various wood quality variables was studied across the clones.

- Results A significant variation was observed in the wood quality between clones, but the variations within clones were not significant. The pilodyn penetration in the standing tree exhibited a strong negative correlation $(r=-0.74)$ with basic density. A moderate but significant positive relationship ( $r=$ 0.61 ) was observed between the acoustic velocity and basic density. The standing tree's acoustic velocity was strongly associated with log velocity $(r=0.88)$. These results suggest that the standing tree measurements namely pilodyn penetration, acoustic velocity and longitudinal growth strain can efficiently be used as fast mass screening methods for wood quality in E. tereticornis.
\end{abstract}

\section{Handling Editor: Jean-Michel Leban}

S. S. Chauhan $(\bowtie)$

School of Forestry, University of Canterbury,

Private Bag 4800,

Christchurch, New Zealand

e-mail: shakti.chauhan@canterbury.ac.nz

S. S. Chauhan

e-mail: shakti32@gmail.com

P. Aggarwal Institute of Wood Science and Technology,

Bangalore, India
- Conclusions The absence of any association of longitudinal growth strain with any of the measured wood quality parameters suggests that superior clones having low growth strains can be selected for solid wood production without compromising other important wood properties. Four clones were identified with superior wood properties suitable for solid wood products.

Keywords Acoustic velocity Clone $\cdot$ Eucalyptus · Growth strain · Wood quality

\section{Introduction}

Worldwide, Eucalyptus species are being planted for pulp and paper production. Furthermore, clonal forestry has improved productivity in terms of increased volume of wood (Lal 2003). However, clones selected for improved morphological traits such as fast growth, have been found to display a significant variation within and between clones in their intrinsic wood quality traits (Gomide 2009; Rao et al. 2002; Raymond et al. 2009). As a result, wood properties relevant to pulpwood production like basic density, fibre characteristics, vessel characteristics, cellulose content, lignin and extractive content have been incorporated in clonal selections to reduce manufacturing costs, increase pulp yield and obtain better quality paper (Ramirez et al. 2009; Raymond and Apiolaza 2004). Recently, interest is increasing in growing Eucalyptus species for high-value sawlogs, quality sawn timber and engineered wood products. This has initiated efforts to incorporate wood quality characteristics relevant for solid wood products into breeding programmes (Henson et al. 2004; Pelletier et al. 2008). 
The properties relevant to solid wood products like structural timber, furniture and flooring are very different from those required for pulp and paper. The main quality requirements for solid wood products are stiffness, strength, stability, aesthetic features and processing ease. In general, the fundamental wood properties determining these product properties are basic density, modulus of elasticity, microfibril angle, anisotropic shrinkage, i.e. varying magnitude of shrinkage in longitudinal, radial and tangential direction, spiral grain and heartwood content (Raymond 2002; Raymond and Apiolaza 2004). In many Eucalyptus species, a high magnitude of longitudinal growth stresses and excessive volumetric shrinkage are major causes for concern. High growth stresses result in the end-splitting of logs, and warping and deformation in boards during sawing leading to poor recovery of quality sawn timber (Kubler 1987), whereas a high volumetric shrinkage has significant commercial consequences in terms of stability and recovery of timber (Greaves et al. 2004; Hai et al. 2009).

Clonal propagation can play an important role in the production of quality sawn wood from the Eucalyptus species as clonal testing leads to the more accurate assessment of genotypes due to the higher heritabilities (that include additive and non-additive genetic effects). Higher genetic gains can be achieved when selected clones are deployed in the field. Many properties for solid wood products have been reported to have moderate to high heritability. A wood's basic density is considered to be one of the most important wood properties and is reported to be strongly under genetic control with heritability ranging from 0.60 to 1 (Raymond 2002; Zobel and Van Buijtenen 1989). The basic density has served as the predominant wood selection criterion for improvement in many species due to its high heritability, relationships with other wood properties such as strength, hardness, fibre coarseness, and relative ease in measurement. Longitudinal growth stresses and shrinkage have been reported to have a moderate to high heritability (Greaves et al. 2004; Henson et al. 2004; Murphy et al. 2005; Pelletier et al. 2008). Young's modulus of elasticity (MoE) is a critical wood property in engineered structures. This property is more directly linked to the end product performance as it is a composite function of microfibril angle and basic density (Evans and Ilic 2001; Lindström et al. 2002). The heritability of $\mathrm{MoE}$ in the Eucalyptus species is reported to be in the range of 0.3-0.5 (Henson et al. 2004; Santos et al. 2004).

There have been significant efforts on finding quick, simple and reliable methods (direct or indirect) for assessing wood properties, particularly in selection where a large number of individuals, families or clones need to be assessed (Raymond and Apiolaza 2004). The pilodyn has been used as an indirect way of segregating standing trees according to wood density classes. Negative correlation coefficients ranging from -0.55 to -0.90 have been observed between pilodyn penetration and outer wood basic density at breast height for various Eucalyptus species (Cown et al. 1981; Greaves et al. 1996). The measurement of acoustic velocity is a well-recognised method for ranking trees or logs according to their stiffness (Dickson et al. 2003; Tsehaye et al. 2000). A quick and reliable determination of dynamic MoE from the acoustic velocity has made it possible to use stiffness as one of the wood properties in the selection for solid wood. The dynamic modulus of elasticity (DMoE) is derived from the wood density $(\rho)$ and acoustic velocity $(V)$ measured at the same moisture content using the following equation (Chauhan and Walker 2006):

$\mathrm{DMoE}=\rho V^{2}$

The acoustic velocity measured in logs and trees have been found to have a moderate to strong association with static $\mathrm{MoE}$ in clear wood samples with a correlation coefficient ranging from 0.45 to 0.90 (Chauhan and Walker 2006; Dickson et al. 2003; Lindström et al. 2002). Furthermore, the acoustic velocity has been found to capture, in part, other wood characteristics like tracheid length, microfibril angle in the S2 layer and even the chemical composition of cell walls (Albert et al. 2002; Evans 2000).

The methods of direct measurement of growth stresses in trees are yet to be established. In practice, peripheral longitudinal growth strains are measured by releasing the growth stresses by cutting fibres all around the point of strain measurement. Generally, growth strains are considered to be a direct indicator of stresses in a tree as stress is proportional to the strain within the elastic limits. The methods of measuring growth strains have been reviewed by many researchers (Kubler 1987; Yoshida and Okuyama 2002). Unconventional approaches of shrinkage measurements using increment cores, small blocks and whole discs have provided opportunities to include wood shrinkage as a selection criterion for dimensional stability in the Eucalyptus species, which is otherwise very time-consuming and costly (Greaves et al. 2004; Pelletier et al. 2008).

India is the world leader in Eucalyptus plantations with an area of 3.94 million hectares (Chezhian et al. 2010) and Eucalyptus tereticornis $\mathrm{Sm}$. is the predominant species due to its fast growth, wide adaptability to varied climatic conditions and relatively high resistance to drought (Rao et al. 2002). Initially, the species was grown to meet the ever increasing demand for pulpwood and fuelwood. Now, it is becoming an important timber resource for solid wood products like furniture (Sharma et al. 2005). This paper aims to rank 14 clones of 9-year-old E. tereticornis Sm., based on the properties relevant to solid wood products. We report the variability in wood properties particularly in 
basic density, acoustic velocity, dynamic MoE, longitudinal growth strains and whole disc volumetric shrinkage among the studied clones. Relationships between the different wood properties were also examined. The study also explores the potential of using pilodyn and acoustic velocity measurements in standing tree to segregate clones according to basic density and stiffness. Relationships between the different wood properties assessed on the standing trees and in wood from the corresponding tree following felling were analysed in order to develop the most appropriate selection strategies.

\section{Material and methods}

Fourteen clones were selected from a vegetative multiplication orchard in which 25 clones of $E$. tereticornis were raised from coppice cuttings by the Institute of Wood Science and Technology, Bangalore in 1998 at Nagarur (latitude, 13 $08^{\prime}$ north; longitude, $77^{\circ} 44^{\prime}$ east), about $35 \mathrm{~km}$ north of Bangalore. The orchard has 25 rows with each individual row having 25 trees corresponding to a specific clone. Trees within a row were planted at $1.5 \mathrm{-m}$ spacing while the distance between the rows was $3 \mathrm{~m}$. The trees were 9 years old at the time of this study. The clones in this study were preselected based on their good growth and tree form in the orchard.

\subsection{Standing tree measurements}

Five trees from each clone were randomly selected in the orchard for standing tree measurements. Over-bark diameter, longitudinal growth strain and pilodyn penetration were measured at the breast height (1.4 $\mathrm{m}$ above ground) in each of the selected trees.

The longitudinal growth strain in trees was measured using the wire strain gauge method (Chauhan and Walker 2004; Yoshida and Okuyama 2002). In this method, a portion of the bark from the vicinity of the measuring point was removed to expose the wood surface which was thoroughly cleaned using cotton to wipe away surface moisture. A $5-\mathrm{mm}$ wire strain gauge of $350-\Omega$ resistance was glued to the cleaned wood surface using a cyanoacrylated-based adhesive. Once the strain gauge was well bonded to the wood surface, it was connected to a purpose built two-channel strain metre in a quarter-bridge configuration. Care was taken to measure growth strains in calm conditions to avoid any significant interference from wind sway. Wood fibres were cut above and below the strain gauge using a hand drill machine $(6-\mathrm{mm}$ drill diameter) to relieve the tensile stress in the fibres. The cut slots were about $15-\mathrm{mm}$ wide and about $20-\mathrm{mm}$ deep (until a constant longitudinal growth strain is recorded). As the slots are made, the fibres in the isolated segment of wood contract longitudinally and expand transversely. A change in strain in the immediate vicinity of the gauge is indicated by the strain metre. The configuration of holes and strain gauge is shown in Fig. 1. The strains in all the trees were measured on the same side (facing north).

The pilodyn penetration measurement as an indirect assessment of wood density near breast height is advocated by Raymond and MacDonald (1998). Therefore, measurements were taken at the breast height on two opposite sides (north and south) of each tree using a 6-J pilodyn tester. A small window was created by removing the bark at the point of measurement and a single pilodyn reading, i.e. the depth of penetration of the flat-nosed pin into the wood was obtained on each side. The mean of the two readings was taken as the pilodyn measurement of a tree.

The acoustic velocity was measured by a device designed at the Institute of Wood Science and Technology, Bangalore and fabricated by Spektronics Ltd., Bangalore. Three specially designed probes were inserted into the wood vertically in line through the bark at an angle of $45^{\circ}$ to the trunk surface. A schematic diagram showing the probe positions and their direction on a tree trunk is shown in Fig. 2. The lower probe was an inert starter probe placed at about $20-30 \mathrm{~cm}$ above the ground pointing upwards. This probe was used to induce a stress wave in the tree trunk. The other two probes were active receiver probes pointing downwards in the stem. The distance between the two receiver probes was $1.3 \mathrm{~m}$. The lower receiver probe was placed at about $30 \mathrm{~cm}$ from the starter probe. The start probe was gently tapped with a light hammer (about $100 \mathrm{~g}$ ) to induce a stress wave along the tree. The arrival time of the stress wave at both receiver probes was recorded. The acoustic velocity was determined by dividing the distance between the receiver probes $(1.3 \mathrm{~m})$ by the difference in stress wave arrival times.

\subsection{Wood property measurements}

Three trees of each clone were felled, and a clear log of about 3-m length was extracted. Immediately after cutting,

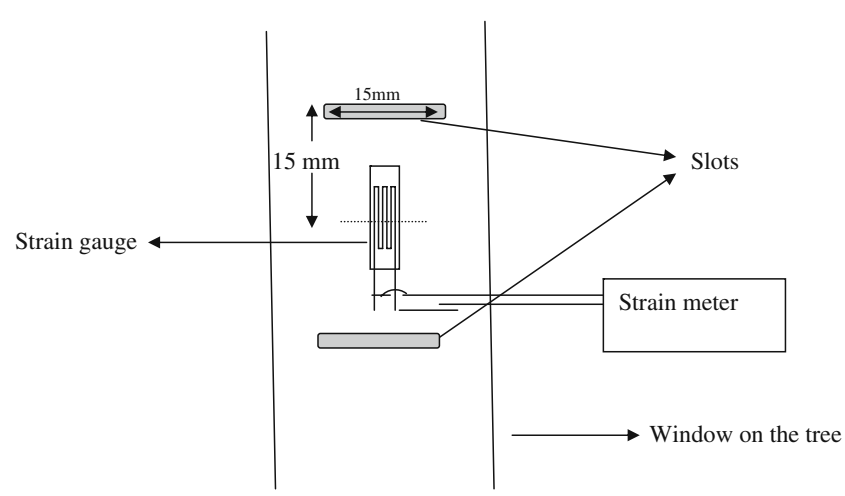

Fig. 1 Schematic presentation of strain measurement in trees 


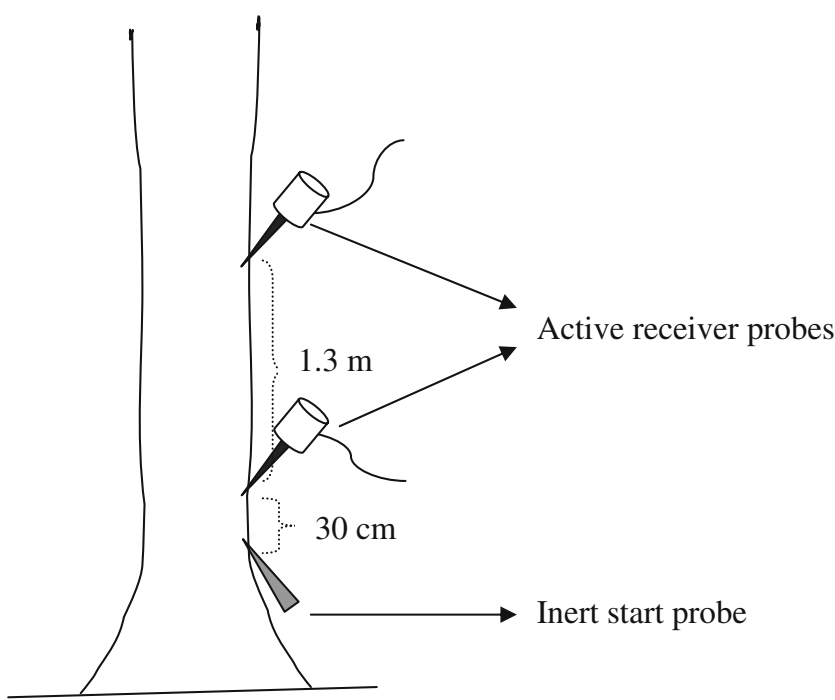

Fig. 2 Schematic diagram of acoustic velocity measurement in trees

both ends were coated with black paint to avoid any moisture loss and transported to the laboratory. These logs were kept in green condition by continuously spraying water until all measurements were completed. First, a 25-mm thick disc from both ends of each log was cut and debarked. These discs were immediately measured for weight and volume to determine the green density. Subsequently, the discs were oven-dried at $103^{\circ} \mathrm{C}$. The dried discs were cooled down to room temperature in an airtight chamber over calcium chloride. The dried and cooled discs were then measured for weight and volume. The disc volume was measured by immersion to an accuracy of 0.1 g. (Archimides' method). The disc volume was measured quickly $(<10$ s) to avoid any water absorption. The wood's basic density and volume shrinkage of the discs were determined from these measurements according to standard formulae (Walker 2006).

The acoustic velocity was measured in the logs by the resonance method using the same device used for the standing trees. The device has capabilities to function in both transit time and resonance modes. In the resonance mode, when a log is tapped at one end, the acoustic waves travel back and forth from end to end within the log resonating at its fundamental frequency and its overtones (Chauhan and Walker 2006). The vibrations were captured using a microphone placed close to the other end. A Fast Fourier Transformation of the captured signal was performed by the inbuilt software to identify resonance frequencies of the log. The acoustic velocity $(V)$ is determined from the frequency of the longitudinal vibration $\left(f_{n}\right)$ and $\log$ length $(l)$ using the following relationship (Bucur 1995):

$V=\frac{2 l f_{n}}{n}$ where $n$ is the order of overtones ( $n=1$ for the fundamental frequency). The fundamental frequency was used to measure the acoustic velocity. The log dynamic modulus of elasticity was determined by multiplying the green density with the square of log velocity using Eq. 1.

\subsection{Data analysis}

The standing trees data were analysed as a one-way analysis of variance (ANOVA) according to the following linear model

$y_{i j}=\mu+C_{i}+e_{i j}$

where $y_{i j}$ was expressed as a function of the overall mean $(\mu)$, clone $i\left(C_{i}\right)$ and a random residual $\left(e_{i j}\right)$ effects. It is assumed that $e_{i j}$ follows an independent and identical normal distribution with variance $\sigma_{e}^{2}$. Multiple post hoc comparisons were performed using a Duncan's multiple range test and significance tests conducted at the $95 \%$ confidence level. A Pearson's correlation analysis was performed to assess the strength of associations between various wood quality traits measured in trees and in corresponding logs. All the analyses were performed with the statistical software SAS version 9.2 (SAS 2008).

\section{Results}

\subsection{Standing tree measurements}

Table 1 summarises the descriptive statistics for the clones as measured in standing trees. The diameter at breast height $(\mathrm{DBH})$ was greatest in clones 1,2 and $6(\mathrm{DBH}>14.5 \mathrm{~cm})$, whereas clones 7 and 14 had relatively poor growth. A large variation was observed in the longitudinal growth strain among clones with clone 14 showing the smallest growth strain $(396 \mu \mathrm{m} / \mathrm{m})$ and clone 8 exhibiting the maximum strain $(1,284 \mu \mathrm{m} / \mathrm{m})$. The mean pilodyn penetration in wood varied from 8.55 to $12.95 \mathrm{~mm}$, whereas the trees' acoustic velocity ranged from $3.24 \mathrm{~km} / \mathrm{s}$ (clone 8 ) to $3.99 \mathrm{~km} / \mathrm{s}$ (clone 1). The ANOVA suggested significant differences between clones in all the measured variables (Table 2). The proximity of clones for their DBH, growth strain, pilodyn penetration and acoustic velocity are shown in Fig. 3. Clones are ranked from highest to the lowest (from left to right) values for individual variables. Clones within a cluster or group do not have significant differences for that specific variable. DBH has only four clusters indicating less variation in radial growth between clones as compared to other variables. The longitudinal growth strain and tree acoustic velocity had six clusters while pilodyn penetration had eight clusters exhibiting a much higher variability between the clones. 
Table 1 Average values of the parameters measured in standing trees of the 14 clones (five trees per clone)

\begin{tabular}{|c|c|c|c|c|}
\hline Clone no. & $\mathrm{DBH}(\mathrm{cm})$ & Tree acoustic velocity $(\mathrm{km} / \mathrm{s})$ & Growth strains $(\mu \mathrm{m} / \mathrm{m})$ & Pilodyn penetration (mm) \\
\hline 1 & $15.06(1.04)$ & $3.99(0.14)$ & $631(244)$ & $9.65(0.4)$ \\
\hline 2 & $14.67(1.10)$ & $3.68(0.17)$ & $800(151)$ & $8.55(1.10)$ \\
\hline 3 & $13.05(0.64)$ & $3.77(0.07)$ & $842(108)$ & $9.95(0.41)$ \\
\hline 4 & $14.2(1.12)$ & $3.56(0.05)$ & $669(92)$ & $9.75(0.95)$ \\
\hline 5 & $12.55(1.59)$ & $3.79(0.11)$ & $778(166)$ & $11.00(1.22)$ \\
\hline 6 & $14.65(1.39)$ & $3.45(0.12)$ & $1010(148)$ & $10.00(1.08)$ \\
\hline 7 & $11.85(1.55)$ & $3.52(0.04)$ & $746(236)$ & $9.48(0.04)$ \\
\hline 8 & $12.26(1.90)$ & $3.24(0.18)$ & $1284(340)$ & $12.95(0.48)$ \\
\hline 9 & $12.61(1.81)$ & $3.62(0.04)$ & $833(160)$ & $10.60(0.89)$ \\
\hline 10 & $13.12(2.11)$ & $3.45(0.06)$ & $775(276)$ & $11.50(0.50)$ \\
\hline 11 & $13.47(1.10)$ & $3.46(0.10)$ & $1061(47)$ & $11.10(0.89)$ \\
\hline 12 & $12.74(1.79)$ & $3.48(0.09)$ & $677(89)$ & $10.75(0.35)$ \\
\hline 13 & $12.64(0.97)$ & $3.47(0.10)$ & $943(97)$ & $11.00(0.82)$ \\
\hline 14 & $12.1(1.08)$ & $3.50(0.11)$ & $396(70)$ & $11.00(0.94)$ \\
\hline
\end{tabular}

Values in the parentheses is standard deviation

\subsection{Wood property measurements}

Variability in green and basic density, log acoustic velocity, $\mathrm{DMoE}$ and whole disc volumetric shrinkage are given in Table 3 . The dynamic modulus of elasticity was determined from the acoustic velocity measured in the $\log$ and the green density. Acoustic velocity is the average of the three values (from three logs per clone), whereas the densities and volumetric shrinkage are the average of six values (two discs from each $\log$ ). As expected, green density had a small variation with the range of $987-1,087 \mathrm{~kg} / \mathrm{m}^{3}$. A large range was observed in other wood properties among the clones. Basic density ranged from 583 to $736 \mathrm{~kg} / \mathrm{m}^{3}$, acoustic velocity ranged from 3.14 to $4.18 \mathrm{~km} / \mathrm{s}$, dynamic MoE ranged from 10.36 to $17.26 \mathrm{GPa}$ and volumetric shrinkage ranged from $15.28 \%$ to $22.81 \%$. Basic density and acoustic velocity were the highest in clone 1 . The lowest basic density and acoustic velocity were observed in clone 10 and clone 8 , respectively. Wood from clone 8 also exhibited the maximum volumetric shrinkage (22.81\%). The lowest volumetric shrinkage was observed in discs from clone 12 .

\subsection{Relationship between traits}

A Pearson's correlation analysis was performed to analyse the relationship between various wood quality parameters (Table 4). The correlation was carried out with pooled data across the clones. Over-bark DBH exhibited a moderate positive relationship with both basic density and acoustic velocity but had no association with growth strains. The longitudinal growth strain in trees did not exhibit any significant association with other measured wood quality variables except a weak positive association with volumetric shrinkage $(r=0.31, P<0.05)$. A strong negative correlation $(r=-0.74)$ was observed between pilodyn measurements on standing trees and basic density of wood. Pilodyn penetration also exhibited a significant negative correlation with
Table 2 Analysis of variance of wood quality variables measured in standing trees

\begin{tabular}{lllccc}
\hline Variable & Source & df & MS & $F$ & $P>F$ \\
\hline DBH & Between clone & 13 & 5.40 & 2.63 & 0.0061 \\
\multirow{2}{*}{ Growth strain } & Within clone & 56 & 2.05 & & \\
& Between clone & 13 & 227,983 & 7.10 & $<0.0001$ \\
Pilodyn & Within clone & 56 & 32,104 & & \\
\multirow{2}{*}{ Tree acoustic velocity } & Between clone & 13 & 5.717 & 10.34 & $<0.0001$ \\
& Within clone & 56 & 0.553 & & \\
& Between clone & 13 & 0.18 & 15.62 & $<0.0001$ \\
\hline
\end{tabular}


Fig. 3 Proximity of the clones (C1-C14) for various variables using Duncan's test (a), DBH (b), growth strains (c), pilodyn penetration (d), tree acoustic velocity. The clones are arranged in order of highest to the lowest values for each variable. Each cluster is presented by two arrow marks joined by a horizontal line. Clones within a cluster are not significantly different

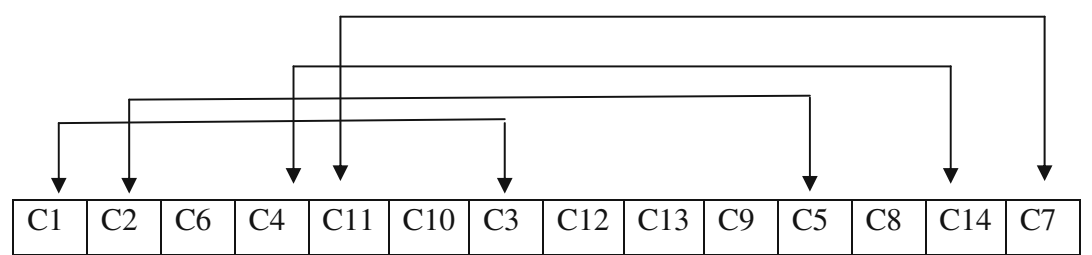

(a) $\mathrm{DBH}$

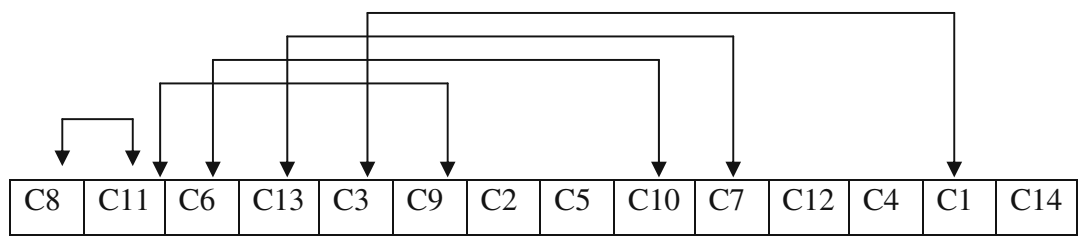

(b) Growth strains

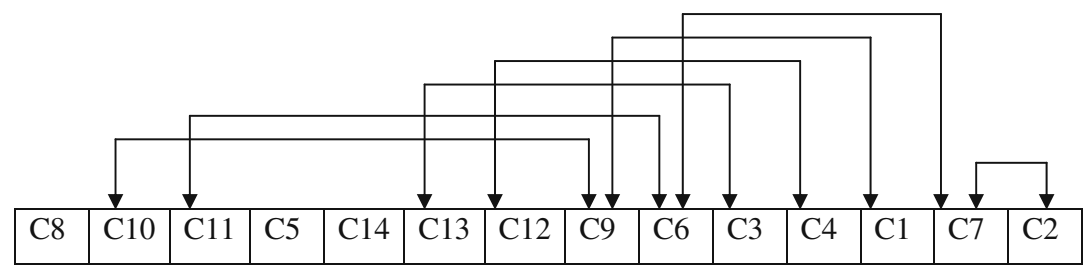

(c) Pilodyn penetration

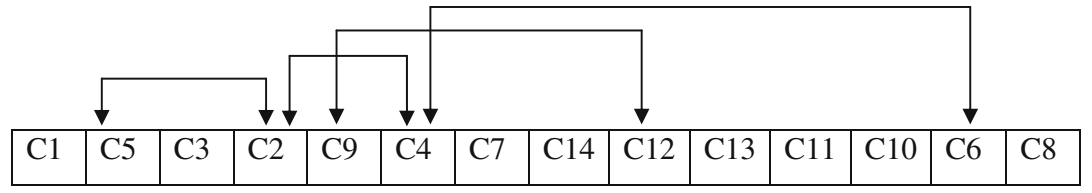

(d) Tree acoustic velocity acoustic velocity in trees and $\operatorname{logs}(r=-0.58, P<0.001)$ and a weak but significant positive correlation $(r=0.35, P<0.05)$ with volumetric shrinkage. The acoustic velocity measured in standing trees was strongly correlated with the velocity measured in $\operatorname{logs}(r=0.88)$ and basic density $(r=0.52)$. Dynamic MoE exhibited a strong positive association with acoustic velocities (tree and $\log$ ) and basic density and negative association with pilodyn penetration.

Table 3 Average values of wood properties in the clones

\begin{tabular}{lccccc}
\hline Clone No & Green density $(\mathrm{kg} / \mathrm{m} 3)$ & Basic density $\left(\mathrm{kg} / \mathrm{m}^{3}\right)$ & Log acoustic velocity $(\mathrm{km} / \mathrm{s})$ & DMoE $(\mathrm{GPa})$ & Volumetric shrinkage $(\%)$ \\
\hline 1 & $987(37)$ & $736(30)$ & $4.18(0.05)$ & $17.26(0.8)$ & $16.87(0.69)$ \\
2 & $1,087(14)$ & $708(02)$ & $3.73(0.10)$ & $15.10(0.6)$ & $17.68(0.16)$ \\
3 & $1,030(17)$ & $640(08)$ & $3.84(0.04)$ & $15.19(0.1)$ & $19.39(0.92)$ \\
4 & $1,039(42)$ & $645(07)$ & $3.73(0.06)$ & $1449(0.7)$ & $17.32(0.40)$ \\
5 & $1,000(72)$ & $658(08)$ & $3.94(0.21)$ & $15.43(0.6)$ & $18.77(0.37)$ \\
6 & $1,049(24)$ & $611(03)$ & $3.57(0.04)$ & $13.35(0.2)$ & $16.03(1.20)$ \\
7 & $1,033(50)$ & $675(12)$ & $3.78(0.11)$ & $14.76(0.1)$ & $16.09(0.04)$ \\
8 & $1,051(34)$ & $609(16)$ & $3.14(0.01)$ & $10.36(0.3)$ & $22.81(1.02)$ \\
9 & $1,067(49)$ & $592(08)$ & $3.65(0.02)$ & $14.25(0.5)$ & $19.87(0.29)$ \\
10 & $1,020(08)$ & $583(14)$ & $3.51(0.03)$ & $12.56(0.3)$ & $17.24(1.80)$ \\
11 & $1,062(23)$ & $641(22)$ & $3.56(0.09)$ & $13.44(0.5)$ & $17.94(1.12)$ \\
12 & $1,022(54)$ & $637(10)$ & $3.37(0.07)$ & $11.56(0.5)$ & $15.28(1.47)$ \\
14 & $1,044(33)$ & $629(18)$ & $3.30(0.14)$ & $11.39(0.7)$ & $16.38(1.06)$ \\
\hline
\end{tabular}

Values in the parentheses is standard deviation 
Table 4 Correlation between wood quality variables $(n=42)$

$T A V$ tree acoustic velocity, $B D$ basic density, $L A V \log$ acoustic velocity, $V S$ volumetric

shrinkage

$* P<0.05 ; * * P<0.01 ; * * * P<$ 0.001

\section{Discussion}

\subsection{Clonal variability in wood properties}

There are significant differences in longitudinal growth strains, wood density, acoustic velocity and volumetric shrinkage among the studied clones of E. tereticornis (Tables 1 and 3). A low standard deviation for each wood property within a clone suggests uniformity in the wood properties within a clone.

Longitudinal growth strain is one of the most important wood quality criteria for the Eucalyptus species as it can substantially reduce the recovery of usable timber. A nearly three folds variation (396 to $1284 \mu \mathrm{m} / \mathrm{m}$ ) was observed among the clones. Such large variations have been reported in growth strains among families and provenances of various Eucalyptus species (Murphy et al. 2005; Raymond et al. 2004). The observed variability signifies the need for a careful selection of clones for solid wood products as growth strain in excess of $700 \mu \mathrm{m} / \mathrm{m}$ is known to cause serious end-splitting and processing defects (Kubler 1987). Four clones (1, 4, 12 and 14) were found to have mean growth strains below this threshold and are the potential clones for solid wood production.

E. tereticornis wood is known to have a high basic density and high volumetric shrinkage. Sharma et al. (2005) have reported a mean basic density and volumetric shrinkage of $710 \mathrm{~kg} / \mathrm{m}^{3}$ and $16.9 \%$, respectively in wood from 10-12 years old (data from five trees), that are comparable to the values observed in this study. Rao et al. (2002) observed lower basic densities in the range of 540 to $598 \mathrm{~kg} / \mathrm{m}^{3}$ in four much younger 4.5 -year-old clones. Since basic density is strongly associated with strength and hardness, a wide range in basic densities observed in clones (583 to $736 \mathrm{~kg} / \mathrm{m}^{3}$ ) suggests future selection based on variability in these properties between the clones.

Very consistent values of volumetric shrinkage within a clone (low standard deviation) indicate the reliability of this form of shrinkage measurements in discs. The variability in shrinkage among clones (15.28\% to $22.81 \%$ ) would result in variability in stability and shape retention of sawn timber. Dried discs were found to exhibit varying degrees of splitting and cracking which can be attributed to the anisotropic shrinkage and collapse in wood (Kang and Lee 2004). The size of a split could provide an indirect method of assessing drying deformations in sawn timber. However, this needs quantitative investigations.

A significant variation in trees and log acoustic velocity among clones implies large differences in their wood stiffness. The top ranked clone for velocity (clone 1) had a $\log$ acoustic velocity 33\% higher than the bottom ranked clone (clone 8). A 33\% difference in the acoustic velocity between the lowest and the highest velocity clones corresponds to about $66 \%$ difference in their respective wood stiffness (17.26 vs $10.36 \mathrm{GPa})$. Although three clones exhibited a dynamic modulus of elasticity of less than $12 \mathrm{GPa}$, the selection for this property appears to be less of a concern as the wood stiffness required for structural applications is reported to be $7.9 \mathrm{GPa}$ (Sharma et al. 2005). However, an early selection for high stiffness may help in lowering the radial gradient in wood properties which is a major cause of dimensional distortion in juvenile wood $(\mathrm{Xu}$ and Walker 2004).

\subsection{Interrelationships in wood properties}

Analysing relationships between different wood properties is of significant importance in understanding the possible trade-offs in selecting clones for a specific wood quality trait. The absence of any relationship between DBH and longitudinal growth strain suggests that the tree growth rate does not influence growth strain. Both the acoustic velocity and the basic density also did not exhibit any significant relationship with the growth strain (Fig. 4). Acoustic velocity is reported to be a surrogate measure of microfibril angle in wood where faster acoustic speed is characterized by low microfibril angle in the wood cell walls (Apiolaza 2009; Chauhan and Walker 2006). Similarly, high growth stresses in wood is linked to extremely low microfibril angle in wood (Okuyama et al. 1994). In such case, a very high acoustic velocity in wood can be anticipated in trees with high longitudinal growth strains. However, the lack of any significant relationship observed between acoustic velocity and growth strains in the study nullifies the 


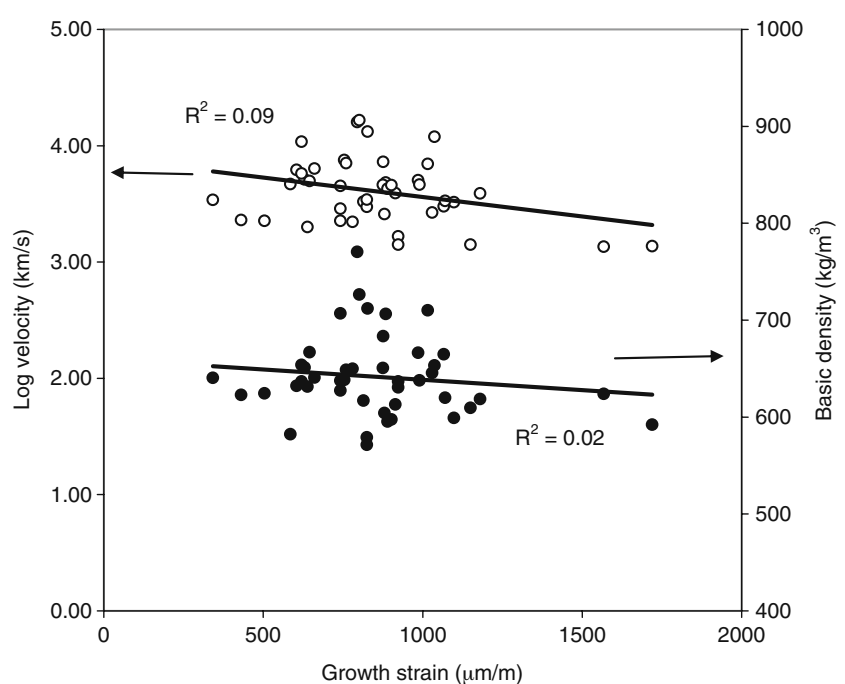

Fig. 4 Relationship of growth strains with basic density and acoustic velocity in logs

anticipated hypothesis. The absence of any association between the two variables has previously been reported in Eucalyptus nitens (Chauhan et al. 2007) and for Eucalyptus globulus by Yang and Ilic (2003).

There have been contradictory reports on the relationship of growth strains in trees/logs with basic density and $\mathrm{MoE}$ of wood among Eucalyptus species. A positive relationship of growth strain with basic density was reported in normal vertical stems of 27-year-old Eucalyptus grandis (Malan and Gerischer 1987), 36-year-old Eucalyptus regnans (Chafe 1990) and 10-year-old E. globulus (Yang and Ilic 2003), but the relationship was absent in the 8-year-old $E$. nitens (Chafe 1990), 10-year-old Eucalyptus cloeziana (Muneri et al. 1999) and 4-year-old Eucalyptus pilularis (Muneri and Leggate 2000). Although Clair et al. (2003) observed a modest positive association between growth strain and modulus of elasticity in the normal wood of chestnut (Castanea sativa Mill.), such an association is absent in the vertical stems of many Eucalyptus species (Chafe 1990; Yang and Ilic 2003). The relationship between the longitudinal growth strain and volumetric shrinkage was statistically significant $(P<0.05)$, but the association does not appear to be strong. The occurrence of tension wood in sample trees could influence the relationship between the growth strain and volumetric shrinkage as tension wood is known to have high longitudinal growth strains and excessive volumetric shrinkage. A weak positive relationship of volumetric shrinkage with growth strain has been reported by Nicholson et al. $(1975,1972)$. A significant positive relationship of the mean tree growth strains with volumetric shrinkage of the outer wood was reported in wood from 9-year-old $E$. nitens trees (Chauhan and Walker 2004). Clair et al. (2003) found a significant positive correlation between growth stress and tangential shrinkage in normal wood, but this was with only two trees of chestnut. Most relationships between longitudinal growth strains and other wood quality variables observed in this study and reported elsewhere appear to be specific to species, site and the sampling methodology. Inconsistent relationships of growth strain and basic density and $\mathrm{MoE}$ emphasise the need for caution in generalizing such an association across species.

Pilodyn measurements in standing trees in this study had a strong negative correlation with basic density (Fig. 5). The observed association between the two variables indicates the potential utility of pilodyn for screening $E$. tereticornis clones for wood basic density. The feasibility of using pilodyn measurements at breast height for an indirect assessment of basic density has already been demonstrated on E. globulus and E. nitens (Greaves et al. 1996; Raymond and MacDonald 1998). Cown et al. (1981) suggested using the pilodyn for the purpose of ranking or grouping genotypes according to density classes. A very high repeatability of pilodyn penetration in Eucalyptus species makes it an efficient tool for high intensity selection in screening or ranking clones according to basic density, although its accuracy depends on the pin diameter and tree age (Greaves et al. 1996). A significant relationship of pilodyn with acoustic velocity and dynamic MoE could partly be due to a significant positive relationship of basic density with acoustic velocity.

The standing tree velocity measured by transit time method was strongly related $(r=0.88)$ to the velocity measured in logs (Table 4). Acoustic velocities by transit time method are known to be sensitive to the local stiffness of the outer wood, whereas velocities by resonance method reflect the volume weighted average stiffness. Absolute differences in the two measurements have been reported (Chauhan and Walker 2006). Dynamic MoEs derived from

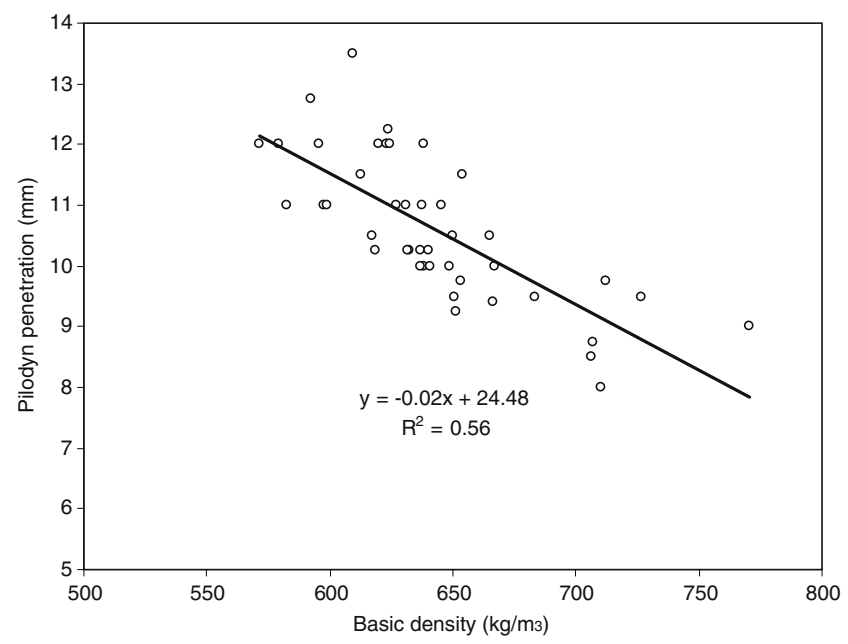

Fig. 5 Relationship of wood basic density with pilodyn penetration in trees 
the resonance method have been found to exhibit very high correlations $(r=0.98)$ with static MoE (Lindström et al. 2002). The strong association between the two velocities implies that, in situ, a single velocity measurement on a young tree of the species would suffice for the selection for wood stiffness. Acoustic velocity was found to have a strong positive relationship with basic density (Fig.6). The results obtained here are in conformity with reports on other Eucalyptus species. Dickson et al. (2003) reported a strong positive association between acoustic velocity measured in logs using the Fakopp tool and basic density in Eucalyptus dunnii. They also found a significant positive association of clear wood MoE with the basic density. The strong correlations between basic density with clear wood $\mathrm{MoE}$ have been reported for E. globulus and E. nitens (McKimm et al. 1988; Yang 1997; Chauhan and Walker 2004). Since the green density was more or less uniform across the clones, nearly $97 \%$ variation in $\mathrm{MoE}$ is explained by the acoustic velocity measured in logs.

The relationships between traits have significant implications in the selection and breeding programmes. A change in one trait is likely to have an effect on the other traits. The absence of any significant relationship of longitudinal growth strains and volumetric shrinkage with either wood basic density or MoE suggests that the clones with low strain can be selected without compromising the wood's basic density and MoE, two other important wood properties for solid wood products.

\subsection{Segregation of clones}

The large variation in wood properties observed in this study among clones emphasises the potential of selection of clones for solid wood production. Clone 8 was found to have the lowest acoustic velocity $(3.14 \mathrm{~km} / \mathrm{s})$ and the

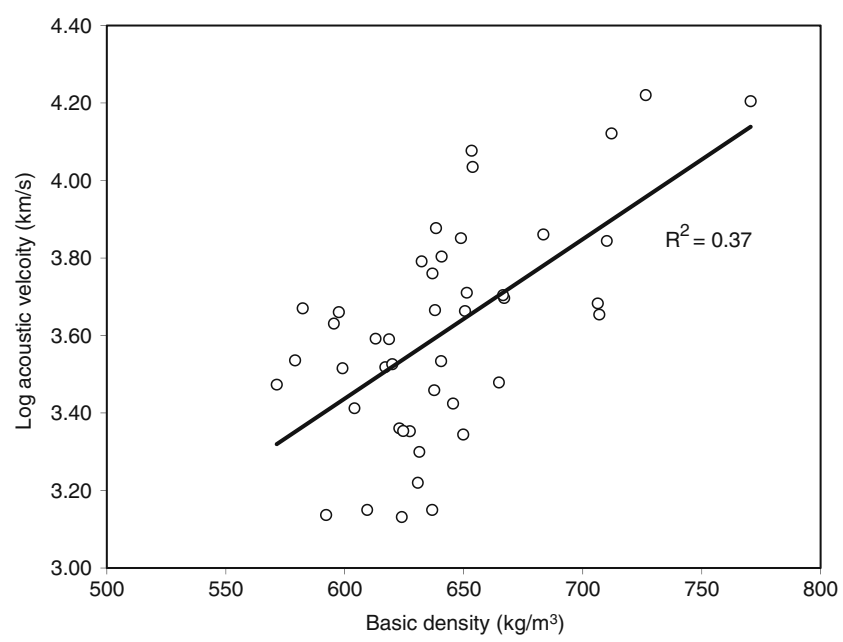

Fig. 6 Relationship between wood basic density and acoustic velocity measured in logs highest volumetric shrinkage $(22.81 \%)$ with a low basic density $\left(609 \mathrm{~kg} / \mathrm{m}^{3}\right)$. The same clone also had the highest level of growth strains $(1,284 \mu \mathrm{m} / \mathrm{m})$ which is large enough to cause serious growth stress-related defects during processing, and a relatively poor radial growth $(\mathrm{DBH}$, $12.26 \mathrm{~cm})$. High volumetric shrinkage and low basic density implies that the wood is prone to develop large deformation and collapse during drying. Therefore, this clone would not be suitable for solid wood production. Among the low growth strain clones (clones 1, 4, 12 and 14), clone 1 has the highest basic density $\left(736 \mathrm{~kg} / \mathrm{m}^{3}\right)$ as well as the highest acoustic velocity $(4.18 \mathrm{~km} / \mathrm{s}$, corresponding to an $\mathrm{MoE}$ of $17.26 \mathrm{GPa}$ ). This clone also exhibited a moderate level of volumetric shrinkage $(16.87 \%)$ compared to other clones. This clone appears to have wood properties suitable for heavy structural applications where dense and stiffer timber is desirable.

For many solid wood products like furniture and light structural applications, a high wood density is not always desirable. Clones 4, 12 and 14 with moderate basic density, acoustic velocity and volumetric shrinkage appear to be potential clones for solid wood production. However, among these three clones, clone 12 and 14 had comparatively low radial growth and therefore could yield less wood volume meaning only clone 4 would be a suitable clone for solid wood production. This selection of clones for a specific end use is primarily based on individual property and overall correlations between traits. In breeding, genetic correlations are used to predict the influence of selection based on one trait on other correlated traits in the next generation and selection index are developed for an efficient selection (Gapare et al. 2009). Therefore, further elaborate studies are required to estimate the genetic correlations between longitudinal growth strains and other wood traits of economic importance to develop selection index for E. tereticornis.

\section{Conclusions}

Significant differences in wood quality among clones provide an opportunity to select superior clones for solid wood production that combine superior growth with desirable wood traits which can be used in further breeding programmes. The selection of clones with low growth strain and volumetric shrinkage could be an important step in quickly improving the quality of solid wood from plantations without compromising wood density and stiffness. Growth strain measurement along with pilodyn and acoustic velocity measurement on standing trees provide a quick and reliable approach for segregating clones of E. tereticornis with properties relevant to solid wood products. 
Acknowledgements The authors express their gratitude to the director and group coordinator of the Institute of Wood Science and Technology, Bangalore for their support in carrying out the study. The authors are also thankful to Prof. John Walker, School of Forestry, University of Canterbury, Christchurch for his valuable comments and improving the language of this paper

\section{References}

Albert DJ, Clark TA, Dickson RL, Walker JCF (2002) Using acoustic to sort radiata pine pulp logs according to fibre characteristics and paper properties. Int For Rev 4(1):12-19

Apiolaza L (2009) Very early selection for wood quality: screening for early winners. Ann For Sci 66:601

Bucur V (1995) Acoustics of wood. CRC Press, Boca Raton, p 284

Chafe S (1990) Relationship among growth strain, density and strength properties in two species of Eucalyptus. Holzforschung 44:431-437

Chauhan S, Walker JCF (2004) Relationships between longitudinal growth strain and some wood properties in Eucalyptus nitens. Aust For 67:254-260

Chauhan S, Walker JCF (2006) Variations in acoustic velocity and density with age, and their interrelationships in radiata pine. For Ecol Manag 229:388-394

Chauhan S, Entwistle K, Walker JCF (2007) Search for a relationship between stress wave velocity and internal stresses in Eucalypts and radiata pine. Holzforschung 61:60-64

Chezhian P, Yasodha R, Ghosh M (2010) Genetic diversity analysis in a seed orchard of Eucalyptus tereticornis. New For 40:85-99. doi:10.1007/s11056-009-9184-1

Clair B, Ruelle J, Thibaut B (2003) Relationship between growth stress, mechanical-physical properties and proportion of fibre with gelatinous layer in chestnut (Castanea sativa Mill.). Holzforschung 57:189-195

Cown DJ, McConchie M, McConchie DL (1981) Developments in pilodyn assessments of tree stems and logs. In: Proceedings of the 11th International Symposium on Nondestructive Testing of Wood, Forest Products Society, Madison. pp 117-122

Dickson R, Raymond C, Joe B, Wilkinson C (2003) Segregation of Eucalyptus dunnii logs using acoustics. For Ecol Manag 179:243-251

Evans R (2000) Measuring wood and fibre properties. In: WTRC Workshop 2000. Wood Technology Research Centre, University of Canterbury, pp.15-20

Evans R, Ilic J (2001) Rapid prediction of wood stiffness from microfibril angle and density. For Prod J 51(3):53-57

Gapare WJ, Baltunis BS, Ivković M, Wu H (2009) Genetic correlations among juvenile wood quality and growth traits and implications for selection strategy in Pinus radiata D. Don. Ann For Sci 66:606. doi:10.1051/forest/2009044

Gomide J (2009) Quality characteristics of elite Eucalyptus clones in Brazil. In: Apiolaza L, Chauhan SS, Walker JCF (eds) Revisiting Eucalyptus 2009, Proceedings of WTRC Workshop, University of Canterbury, pp 29-40

Greaves B, Borralho N, Raymond C, Farrington A (1996) Use of pilodyn for the indirect selection of basic density in E. nitens. Can J For Res 26:1643-1650

Greaves B, Hamilton M, Pilbeam D et al. (2004) Genetic variation in commercial properties of six and 15-year-old Eucalyptus globulus. In: Proceedings of IUFRO Conference-Eucalyptus in a Changing World, Aveiro, 11-15 October 2004

Hai PH, Jansson G, Hannrup B, Harwood C, Thinh HH (2009) Use of wood shrinkage characteristics in breeding of fast-grown Acacia auriculiformis A. Cunn. ex Benth in Vietnam. Ann For Sci 66:611. doi:10-1051/forest/2009048

Henson M, Boyton S, Davies M et al. (2004) Genetic parameters of wood properties in a 9-year-old $E$. dunnii progeny trial in NSW, Australia. In: Proceedings of IUFRO Conference-Eucalyptus in a Changing World, Averio

Kang W, Lee N (2004) Relationship between radial variations in shrinkage and drying defects of tree discs. J Wood Sci 50:209216

Kubler H (1987) Growth stresses in trees and related wood properties. For Abstr 48:131-189

Lal P (2003) Clonal Eucalyptus plantations in India. In: Turnbull JW (ed) Eucalypts in Asia: Proceedings of an International Conference held in Zhanjiang, Guangdong, 7-11 April 2003, ACIAR Proceedings No 111, pp 16-21

Lindström H, Harris P, Nakada R (2002) Methods for measuring stiffness of young trees. Holz Roh Werkst 60(3):165-174

Malan FS, Gerischer GFR (1987) Wood property differences in South African grown Eucalyptus grandis trees of different growth stress intensity. Holzforschung 41:331-335

McKimm RJ, Waugh G, Northway RL (1988) Utilisation potential of plantation-grown Eucalyptus nitens. Aust For 51:63-71

Muneri A, Leggate W (2000) Wood properties and sawn timber characteristics of fast, plantation grown 4-year-old Eucalyptus pilularis. In: Opportunities for the New Millennium, proceedings of Australian Forest Growers 2000 Conference, Cairns, September 2000 , pp. 1-13

Muneri A, Leggate W, Palmer G (1999) Relationships between surface growth strain and some tree, wood and sawn timber characteristics of Eucalyptus cloeziana. S Afr For J 186:41-49

Murphy T, Henson M, Vanclay J (2005) Growth stress in Eucalyptus dunnii. Aust For 68(2):144-149

Nicholson JE, Campbell GS, Bland DE (1972) Association between wood characteristics and growth stress level: a preliminary study. Wood Sci 5:109-112

Nicholson JE, Hillis WE, Ditchburne N (1975) Some tree growthwood property relationships of Eucalyptus. Can J For Res 5:424 432

Okuyama T, Yamamoto H, Yoshida M, Hattori Y, Archer RR (1994) Growth stresses in tension wood: role of microfibrils and lignification. Ann For Sci 51:291-300

Pelletier MC, Henson M, Boyton S, Thomas D, Vancaly JK (2008) Genetic variation in dimensional stability of Eucalyptus pilularis (Smith) assessed using increment cores and test blocks. N Z J For Sci 38(1):194-210

Ramirez M, Rodriguez J, Peredo M, Valenzuela S, Mendonca R (2009) Wood anatomy and biometric parameters variation of $E$. globulus clones. Wood Sci Technol 43:131-141

Rao RV, Shashikala S, Sreevani P, Kothiyal V, Sarma CR, Lal P (2002) Within tree variation in anatomical properties of some clones of Eucalyptus tereticornis Sm. Wood Sci Technol 36:271285

Raymond C (2002) Genetics of Eucalyptus wood properties. Ann For Sci 59:525-531

Raymond C, Apiolaza L (2004) Incorporating wood quality and deployment traits in E. globulus and E. nitens. In: Walter C, Carson M (eds) Plantation forest Biotechnology for the 21st Century, pp. 87-99 ISBN: 81-7736-228-3

Raymond C, MacDonald A (1998) Where to shoot your pilodyn: within-tree variation in basic density in plantation E. globulus and E. nitens in Tasmania. New For 15:205-221

Raymond C, Kube P, Pinkard L, Savage L, Bradley A (2004) Evaluation of non-destructive methods of measuring growth stress in E. globulus: relationships between strain, wood properties and stress. For Ecol Manag 190:187-200 
Raymond C, Henson M, Shepherd S et al. (2009) Quantitative and molecular genetic control of wood properties and chemistry in Eucalyptus pilularis. In: Apiolaza LA, Chauhan SS, Walker JCF (eds) Revisiting Eucalyptus 2009, Proceedings of WTRC Workshop, University of Canterbury, pp 13-28

Santos PET, Geraldi IO, Garcia JN (2004) Estimates of genetic parameters of wood traits for sawn timber production in Eucalyptus grandis. Genet Mol Bio 27(4):567-573

SAS Institute Inc (2008) SAS/STATS procedures guide, 92nd edn. SAS Institute Inc., Cary

Sharma SK, Rao RV, Shukla SR, Kumar P, Sudheendra R, Sujatha M, Dubey YM (2005) Wood quality of coppiced Eucalyptus tereticornis for value addition. IAWA J 26(1):137-147

Tsehaye A, Buchanan AH, Walker JCF (2000) Sorting of logs using acoustics. Wood Sci Technol 34(4):337-344
Walker JCF (2006) Primary wood processing — principles and practice. Springer, Dordrecht, p 596

$\mathrm{Xu}$ P, Walker JCF (2004) Stiffness gradients in radiata pine trees. Wood Sci Technol 38:1-9

Yang JL (1997) Effect of density variation on strength properties of plantation grown Eucalyptus globulus Labill. J Inst Wood Sci $14: 180-184$

Yang J, Ilic J (2003) A new method of determining growth stress and relationships between associated wood properties of Eucalyptus globulus Labill. Aust For 66:153-157

Yoshida M, Okuyama T (2002) Techniques for measuring growth stress on the xylem surface using strain and dial gauges. Holzforschung 56:461-467

Zobel B, Van Buijtenen JP (1989) Wood variation: its causes and control. Springer, Berlin, p 363 